Article

\title{
Evaluation of Petroleum Resin in Rubberized Asphalt Binder
}

\author{
Hyun Hwan Kim ${ }^{1} \mathbb{D}$, Mithil Mazumder ${ }^{1}$, Moon-Sup Lee ${ }^{2, * \mathbb{D}}$ and Soon-Jae Lee ${ }^{1} \mathbb{D}$ \\ 1 Department of Engineering Technology, Texas State University, San Marcos, TX 78666, USA; \\ k_h82@txstate.edu (H.H.K.); m_m624@txstate.edu (M.M.); SL31@txstate.edu (S.-J.L.) \\ 2 Korea Institute of Civil Engineering and Building Technology, Goyang 10223, Korea \\ * Correspondence: truepath@kict.re.kr
}

check for

updates

Citation: Kim, H.H.; Mazumder, M.; Lee, M.-S.; Lee, S.-J. Evaluation of Petroleum Resin in Rubberized Asphalt Binder. Sustainability 2021, 13, 9319. https://doi.org/10.3390/ su13169319

Academic Editor: Nicu Bizon

Received: 1 July 2021

Accepted: 14 August 2021

Published: 19 August 2021

Publisher's Note: MDPI stays neutral with regard to jurisdictional claims in published maps and institutional affiliations.

Copyright: (c) 2021 by the authors. Licensee MDPI, Basel, Switzerland. This article is an open access article distributed under the terms and conditions of the Creative Commons Attribution (CC BY) license (https:// creativecommons.org/licenses/by/ $4.0 /)$.

\begin{abstract}
The crumb rubber modified (CRM) binder was evaluated considering the general operating temperatures of high, intermediate, and low temperatures. CRM binders were produced with four different contents $(0,5,10$, and 15\%) using the base asphalt binder (PG64-22). Then, they were artificially aged by a rolling thin-film oven (RTFO) and pressure aging vessel (PAV). Superpave binder tests using a rotational viscometer (RV), dynamic shear rheometer (DSR), and bending beam rheometer (BBR) was applied to characterize the performance of the original and aged binders. Multiple stress creep recovery (MSCR) tests were also performed for deeper rutting characterization. The results of this study are as follows: (1) the presence of PR increases the binder viscosity, (2) the integration of CRM greatly improved the rutting resistance of the binder, and it was found that PR also improved the rutting characteristics, and (3) it is observed that PR is detrimental to the cracking properties of CRM binders.
\end{abstract}

Keywords: CRM binder; PR; rutting; cracking; MSCR

\section{Introduction}

As an ecofriendly construction material, crumb rubber modifier is widely applied to durable asphalt pavement. A huge amount of scrap tires (about 40 million tires) are disposed of in landfills in the United States [1]. The application of crumb rubber in asphalt pavement is already being used as an alternative method that solves these wasted tires. In addition, by adding crumb rubber, the stiffness and elasticity are increased at high temperatures to improve the rutting characteristics [2]. According to the previous studies [3,4], it enhances coating film on the mixture's aggregate. Eventually, it extends the pavement life as a sustainable material. Consequently, blending crumb rubber with a base asphalt binder and applying it to pavement construction improve the durability of the road and has a positive effect on stiffness at low temperatures and noise from traffic [5-12].

Crumb rubber modified (CRM) binder has numerous advantages related to environment and pavement performance $[13,14]$. CRM binder has a different dispersion mechanism compared to other polymer modified asphalt (PMA) binders. It is not homogeneous, like a styrene-butadiene-styrene (SBS) PMA binder. Individual rubber particles are scattered in the binder and swell after absorbing the oil. Petroleum resin (PR) is one of the petroleum refining products from adhesives that use low-molecular-weight thermoplastic hydrocarbon resins [15]. According to the previous research [16], PR is sufficient for enhancing the compatibility of asphalt binder with a polymer additive. In this study, PR is incorporated into CRM asphalt binder to investigate its efficacy to improve the binder performances with better compatibility.

This study aims to evaluate the effect of PR in CRM asphalt binders. The rolling thinfilm oven (RTFO) and pressure aging vessel (PAV) processes were utilized to produce aged binder samples. A set of Superpave binder tests were accomplished to evaluate the material at three aging states (original, short aging, and long aging). Furthermore, multiple stress creep recovery (MSCR) tests were used to effectively evaluate the permanent deformation properties. The experimental design is shown in Figure 1. 


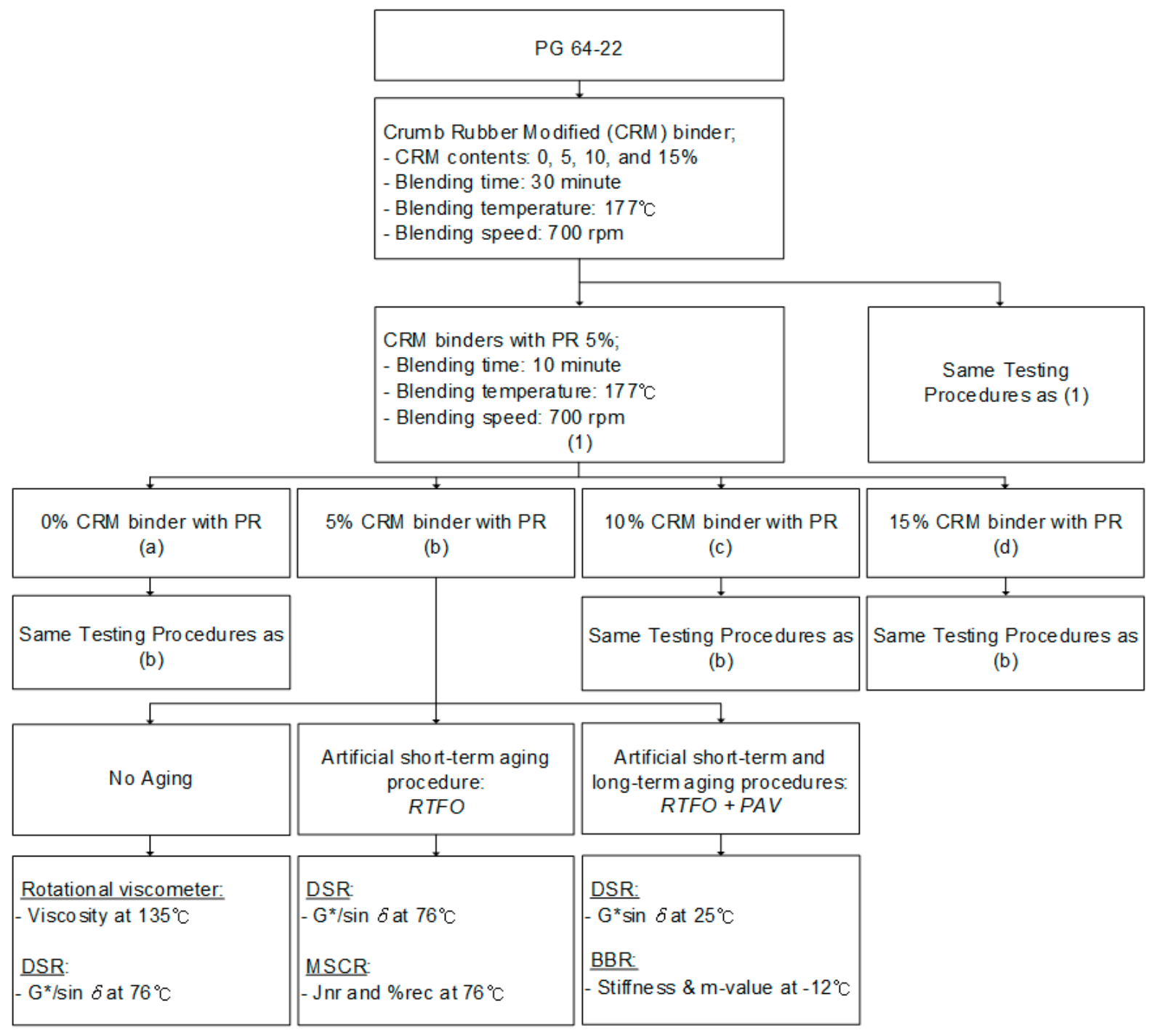

Figure 1. Flow chart of experimental design procedures.

\section{Experimental Design}

\subsection{Materials}

In this study, performance grade (PG) 64-22 was used as the default binder. Table 1 shows the base binder properties. Table 2 shows the gradation of crumb rubber. The applied percentages of CRM were $5 \%, 10 \%$, and $15 \%$ by weight of the base binder. CRM binder was produced with an open blade mixer at $177^{\circ} \mathrm{C}$ for $30 \mathrm{~min}$ with $700 \mathrm{rpm}$, considering the modification mechanism of polymer additives. One batch of CRM is consumed to keep experiment consistency.

Table 1. Properties of asphalt binder (PG 64-22).

\begin{tabular}{ccc}
\hline Aging States & Test Properties & Test Result \\
\hline Unaged Binder & Viscosity @ $135^{\circ} \mathrm{C}(\mathrm{Pa}-\mathrm{S})$ & 0.531 \\
\cline { 2 - 3 } & $\mathrm{G}^{*} / \sin \delta @ 64^{\circ} \mathrm{C}(\mathrm{Kpa})$ & 1.415 \\
\hline RTFO Aged Residual & $\mathrm{G}^{*} / \sin \delta @ 64^{\circ} \mathrm{C}(\mathrm{Kpa})$ & 2.531 \\
\hline $\begin{array}{c}\text { Rtfo }+ \text { Pav } \\
\text { Aged Residual }\end{array}$ & $\mathrm{G}^{*} \sin \delta @ 25^{\circ} \mathrm{C}(\mathrm{Kpa})$ & 2558 \\
\cline { 2 - 3 } & Stiffness $@-12{ }^{\circ} \mathrm{C}(\mathrm{Mpa})$ & 287 \\
\hline
\end{tabular}


Table 2. The gradation of crumb rubber used in this study.

\begin{tabular}{ccc}
\hline \multirow{2}{*}{ Sieve No. $(\mu \mathrm{m})$} & \multicolumn{3}{c}{ Ambient CRM } \\
\cline { 2 - 3 } & \% Cumulative Retained & \% Cumulative Retained \\
\hline $30(600)$ & 0 & 0 \\
\hline $40(425)$ & 91.0 & 9.0 \\
\hline $50(300)$ & 59.1 & 40.9 \\
\hline $80(180)$ & 26.2 & 73.8 \\
\hline $100(150)$ & 18.6 & 81.4 \\
\hline $200(75)$ & 0 & 100.0 \\
\hline
\end{tabular}

The C9 petroleum resin (PR) used in this study is shown in Figure 2. A total of 5\% of C9 PR is added into CRM binders. C9 PR is a byproduct of the fractionation of C9 aromatics produced by steam crackers of petrochemicals to produce ethylene and propylene. C9 PR is considered to have the potential capability to improve the properties of asphalt binders. Therefore, it is expected that the performance and grade of CRM binders can be upgraded through the addition of PR. The following mixing conditions were used: $177^{\circ} \mathrm{C}$ for $5 \mathrm{~min}$ by an open blade mixer at $700 \mathrm{rpm}$.

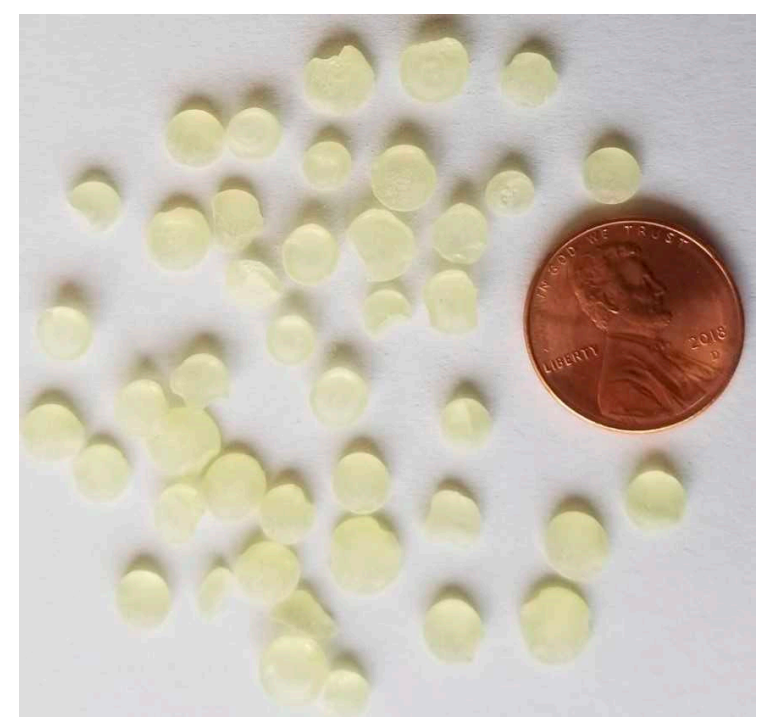

Figure 2. Petroleum resin (PR).

\subsection{Superpave Binder Tests}

The Superpave asphalt binder test is performed to characterize the binder performance in three stages of its life (in its original condition, after mixing and application, and after aging in use).

Viscosity test (AASHTO T 316), dynamic shear rheometer (DSR) test (AASHTO T 315), and bending beam rheometer (BBR) test (AASHTO T 313) are selected considering viscosity, rutting, and cracking properties. For each test, three replicated samples were produced and tested, and the average result was reported. Brookfield rotational viscometer measures the binder viscosity using a number 27 spindle at $135^{\circ} \mathrm{C}$. DSR test at a frequency of 10 radians per second, which is equal to approximately $1.59 \mathrm{~Hz}$, was performed to determine the $\mathrm{G}^{*} / \sin \delta$ of asphalt binders in the original state (unaged) and short-time aged state. Fatigue cracking properties of long-term aged binder (RTFO + PAV residual) were evaluated by measuring $\mathrm{G}^{*} \sin \delta$ at intermediate temperature, $25^{\circ} \mathrm{C}$. Asphalt beams sample $(125 \times 6.35 \times 12.7 \mathrm{~mm})$ were made with a long-term aged binder $(\mathrm{RTFO}+\mathrm{PAV}$ residual sample) to measure creep stiffness (S) at $-12{ }^{\circ} \mathrm{C}$ performing a BBR test. Then, 
$100 \mathrm{~g}$ of weight was loaded on the asphalt binder beam supported at both ends, and the deflection of the center point was continuously measured.

\subsection{Multiple Stress Creep Recovery (MSCR) Tests}

The MSCR test of the rubberized asphalt binder was performed using the same DSR equipment.

This test was conducted following AASHTO TP 70 specifications at $76{ }^{\circ} \mathrm{C}$. Tests were operated with short-term aged binder samples to be examined in creep and recovery at two stress levels: 0.1 and $3.2 \mathrm{kPa}$. The nonrecoverable creep compliance $\left(\mathrm{J}_{\mathrm{nr}}\right)$ and percent recovery (\%rec) are derived from the MSCR test analysis as the test results. As can be seen in Figure 3, each sample experiences creep loading and unloading cycles at stress levels for 1 and $9 \mathrm{~s}$, respectively, with 10 cycles of loading applied at each stress level, 0.1 and $3.2 \mathrm{kPa}$. The MSCR test results, the nonrecoverable creep compliance $(\mathrm{Jnr})$ and recovery rate (\%rec) are calculated to quantify the rutting sensitivity of the asphalt binder. Nonrecoverable creep compliance $\left(\mathrm{J}_{\mathrm{nr}}\right)$, determined by dividing the irreversible shear strain by the shear stress, is used to evaluate the rutting potential of an asphalt binder.

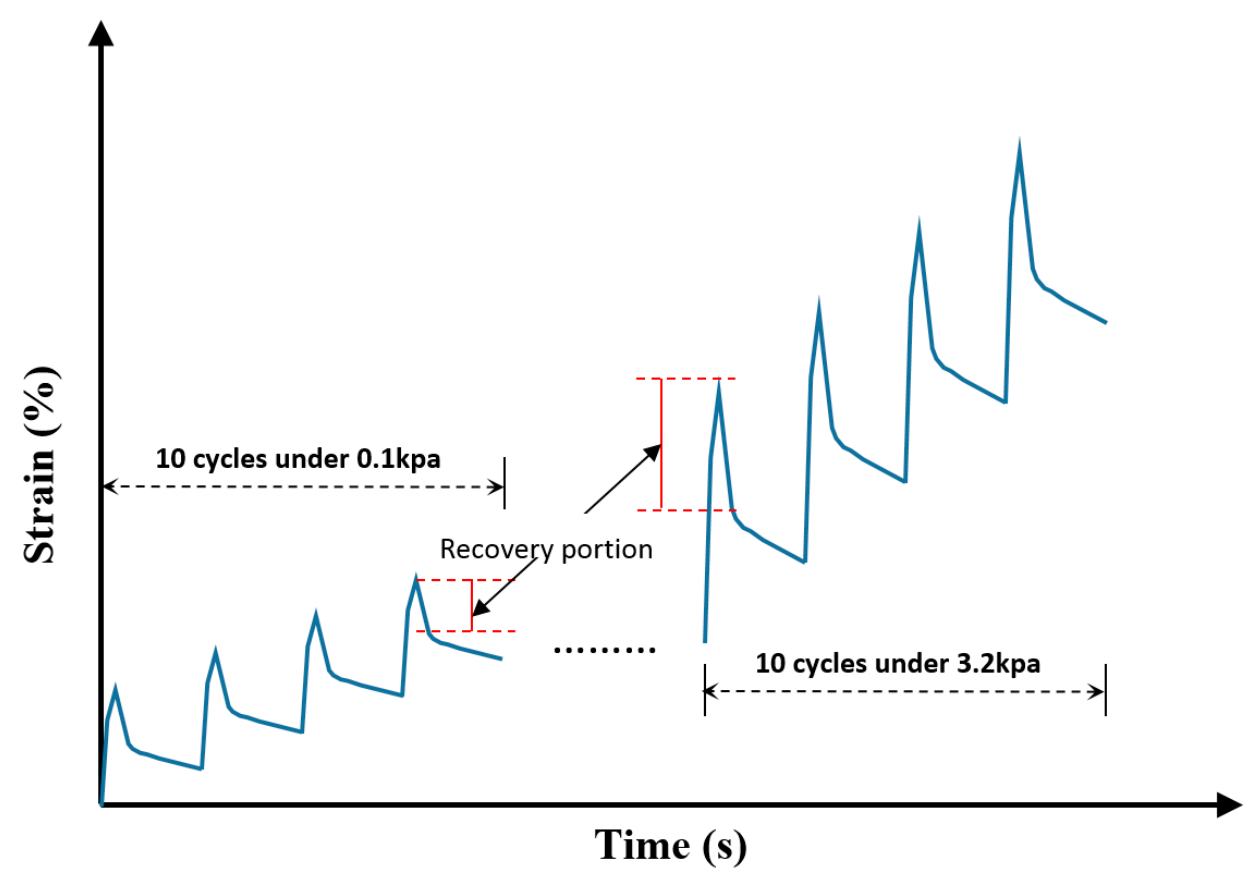

Figure 3. 10 cycles of creep and recovery at two stress levels of 0.1 and $3.2 \mathrm{kPa}$.

\subsection{Statistical Analysis Method}

Statistical analysis system (SAS) program was applied to perform the statistical analysis based on analysis of variance (ANOVA) and Fisher's least significant difference (LSD) comparison with $\alpha=0.05$. LSD is defined as the observed difference between the two sample means required to declare the corresponding population means difference. ANOVA was conducted to find out if there were any significant differences between the sample means. In this analysis, the significance level was 0.95 , indicating a $95 \%$ chance that each finding was true. LSD was calculated after using ANOVA to determine that there was a difference between the sample means. When the LSD was calculated, the mean of the samples of all pairs was compared. Population means were declared statistically different if the difference between the two sample means was greater than or equal to the LSD [17]. 


\section{Results and Discussions}

\subsection{Rotational Viscosity}

In order to determine the asphalt mixing temperature in the field, the viscosity of the binder must be measured first. This is because asphalt binders are intimately related to the ability to pump and coat aggregates in the plant. The viscosity test results measured at $135^{\circ} \mathrm{C}$ are shown in Figure 4 . According to the results, the addition of crumb rubber is effective in increasing the viscosity. In addition, all binder viscosity values show a proportionally increasing trend as CRM content increases. With a 5\% increase in CRM percentage, the viscosity values are increased by approximately $50 \%$ on average. On the other hand, all asphalt binders containing $5 \%$ PR showed higher binder viscosity than those without PR. The viscosity is increased by $25 \%$ on average by the addition of the PR compared to the CRM binders without PR. In addition, as the CRM content increased, the CRM binder's viscosity is increased due to the addition of PR. At $0 \%$ content, it is increased by $15 \%$, whereas at $15 \%$ CRM content, the viscosity is increased by $30 \%$, doubled. This result means that the higher the CRM binder's absolute viscosity, the greater the effect of increasing the viscosity by adding PR. All viscosity results satisfied the maximum limit, $3000 \mathrm{cP}$, although it showed different values depending on both additives and contents.

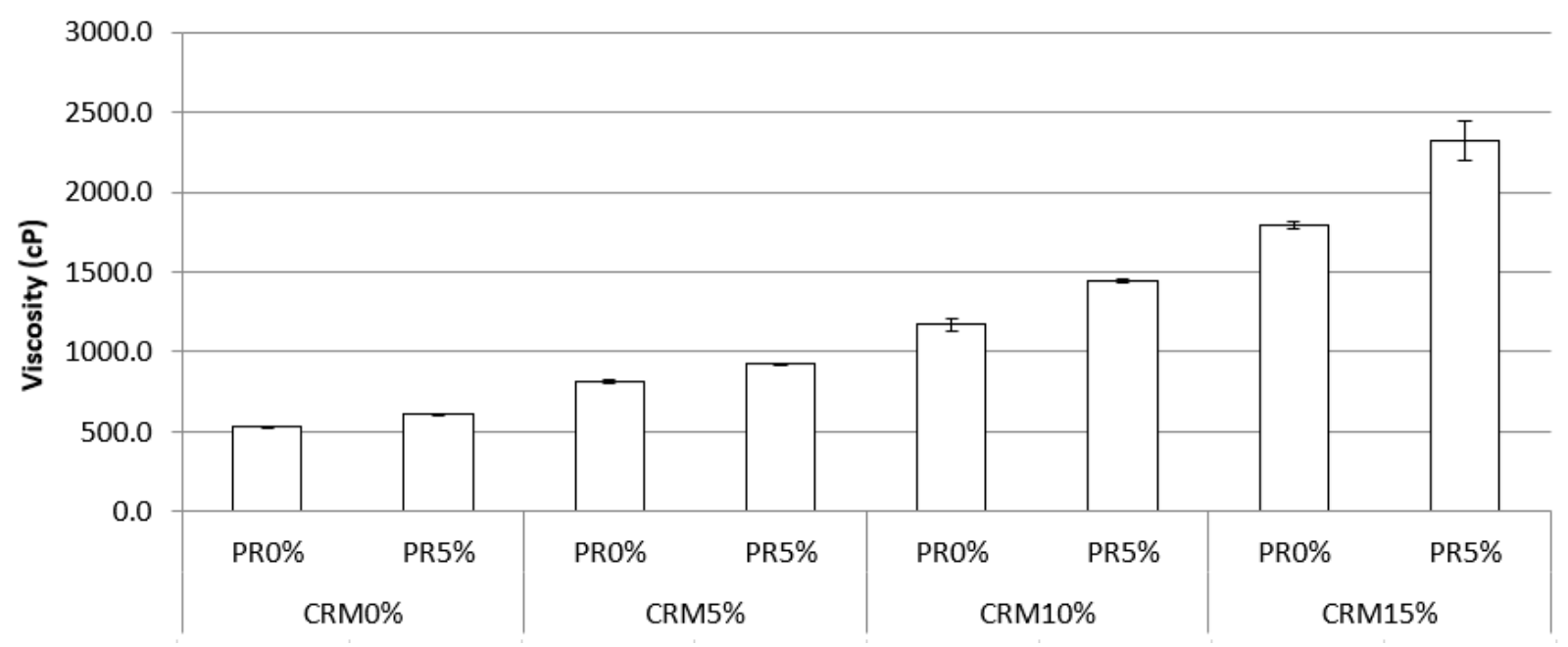

Figure 4. Viscosity of the CRM binders with PR at $135^{\circ} \mathrm{C}$. Note: The error bar indicates the standard deviation.

The statistical significance of the viscosity with a function of CRM contents and PR is examined, and the results are shown in Table 3. The CRM contents have a significant effect on the viscosity values. In addition, a statistically significant difference is observed with the addition of $5 \%$ PR. This means that there is a noticeable effect of increasing the viscosity by the CRM content and PR.

\subsection{Rutting Property}

\subsubsection{Dynamic Shear Rheometer (DSR) Test}

According to the DSR test results, it is interpreted that the higher $\mathrm{G}^{*} / \sin \delta$, the stronger the binder is against permanent deformation at higher temperatures. $\mathrm{G}^{*} / \sin \delta$ values of original and short-term aged CRM binders were measured at $76{ }^{\circ} \mathrm{C}$. Figure 5 illustrates the test results for both original and short-term aged binders. First of all, it was found that the addition of CRM improves plastic deformation resistance. The value of $\mathrm{G}^{*} / \sin \delta$ is increased as the amount of rubber added is increased, and the maximum value is observed in the binder containing 15\% CRM. These results are common both before and after aging states. In addition, the addition of PR is expected to have a positive effect on the rutting property of the pavement. All of the modified asphalt binders, including the base binder, showed a higher $\mathrm{G}^{*} / \sin \delta$ value than the binders without PR in the binders with $5 \%$ PR added before and after aging. These results indicate that both additives improved the 
plastic deformation resistance and are expected to be used with a PR rather than using only CRM to enhance the rutting property. On the other hand, from the additional amount of $10 \%$ or more, the minimum usable value (original $=1.0 \mathrm{kPa}$, short-term aged $=2.2 \mathrm{kPa}$ ) was passed.

Table 3. Statistical analysis results of the viscosity as a function of CRM content and addition of PR $(\alpha=0.05)$.

\begin{tabular}{|c|c|c|c|c|c|c|c|c|c|c|}
\hline & \multirow{3}{*}{ Viscosity } & & \multicolumn{8}{|c|}{ CRM Content } \\
\hline & & & \multicolumn{2}{|c|}{$0 \%$} & \multicolumn{2}{|c|}{$5 \%$} & \multicolumn{2}{|c|}{$10 \%$} & \multicolumn{2}{|c|}{$15 \%$} \\
\hline & & & PR0\% & PR5\% & PR0\% & PR5\% & PR0\% & PR5\% & PR0\% & PR5\% \\
\hline \multirow{6}{*}{ 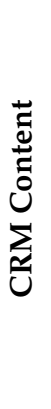 } & 0 & PR0\% & - & 0 & 1 & 1 & 1 & 1 & 1 & 1 \\
\hline & 0 & PR5\% & & - & 1 & 1 & 1 & 1 & 1 & 1 \\
\hline & $\therefore$ & PR0\% & & & - & 1 & 1 & 1 & 1 & 1 \\
\hline & in & PR5\% & & & & - & 1 & 1 & 1 & 1 \\
\hline & $\stackrel{\circ}{\circ}$ & $\begin{array}{l}\text { PR0\% } \\
\text { PR5\% }\end{array}$ & -- & & & 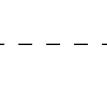 & - & $-\frac{1}{-}$ & $\frac{1}{1}-$ & $--\frac{1}{1}-$ \\
\hline & $\begin{array}{l}\stackrel{0}{10} \\
\stackrel{10}{\longrightarrow}\end{array}$ & $\begin{array}{l}\text { PR0\% } \\
\text { PR5\% }\end{array}$ & $-\ldots$ & - & & - & & 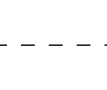 & - & $--\frac{1}{-}-$ \\
\hline
\end{tabular}

0: nonsignificant, 1: significant.

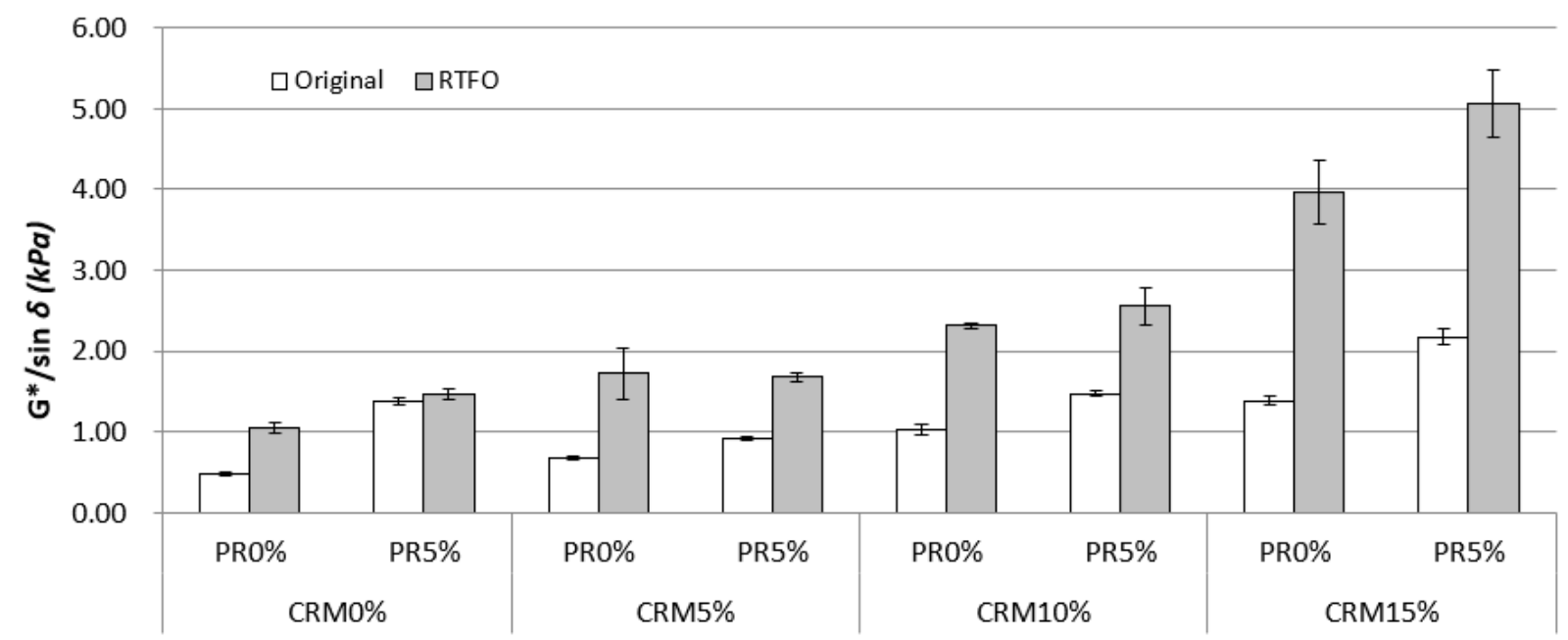

Figure 5. $\mathrm{G}^{*} / \sin \delta$ of the $\mathrm{CRM}$ binders with $\mathrm{PR}$ at $76{ }^{\circ} \mathrm{C}$. Note: The error bar indicates the standard deviation.

The statistical analysis of the $\mathrm{G}^{*} / \sin \delta$ value as a function of the addition of PR and CRM contents was investigated, and the results are shown in Table 4. In general, the data illustrate that CRM content has a significant effect on significant $\mathrm{G}^{*} / \sin \delta$ value in both aging states. The impact of the addition of PR was found to be statistically significant in the results before aging. Still, after aging, the results showed that the addition of $5 \%$ PR had no significant effect on the CRM binders except for the 15\% CRM content. 
Table 4. Statistical analysis results of the $\mathrm{G}^{*} / \sin \delta$ as a function of CRM content and addition of PR $(\alpha=0.05)$; (a) original, and (b) RTFO.

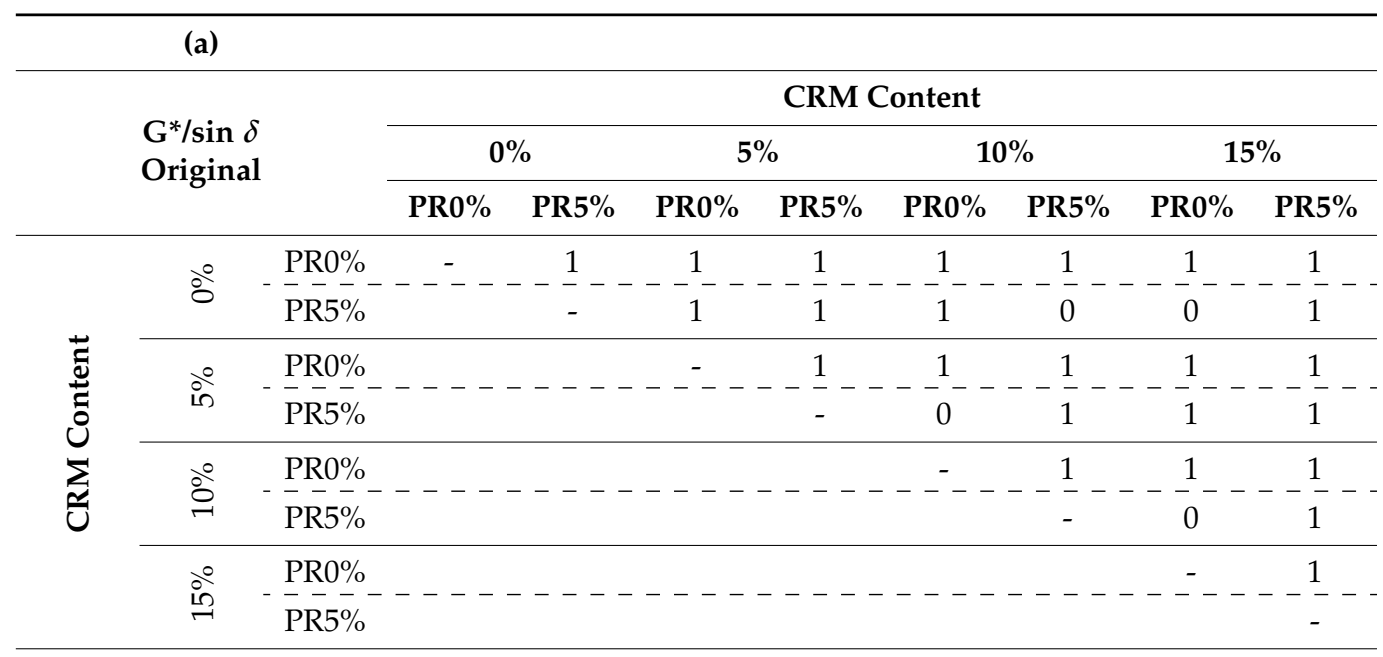

(b)

\begin{tabular}{|c|c|c|c|c|c|c|c|c|c|c|}
\hline \multirow{3}{*}{\multicolumn{3}{|c|}{$\begin{array}{c}\mathrm{G}^{*} / \sin \delta \\
\text { Short-Term Aged }\end{array}$}} & \multicolumn{8}{|c|}{ CRM Content } \\
\hline & & & \multicolumn{2}{|c|}{$0 \%$} & \multicolumn{2}{|c|}{$5 \%$} & \multicolumn{2}{|c|}{$10 \%$} & \multicolumn{2}{|c|}{$15 \%$} \\
\hline & & & PR0\% & PR5\% & PR0\% & PR5\% & PR0\% & PR5\% & PR0\% & PR5\% \\
\hline \multirow{6}{*}{ 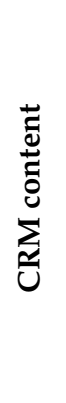 } & $a^{\circ}$ & PR0\% & - & 0 & 1 & 1 & 1 & 1 & 1 & 1 \\
\hline & 0 & PR5\% & & - & 0 & 0 & 1 & 1 & 1 & 1 \\
\hline & $\alpha^{0}$ & PR0\% & & & - & $\underline{0}$ & 1 & 1 & 1 & 1 \\
\hline & in & PR5\% & & & & - & 1 & 1 & 1 & 1 \\
\hline & $\stackrel{\circ}{\circ}$ & $\begin{array}{l}\text { PR0\% } \\
\text { PR5\% }\end{array}$ & -- & & & 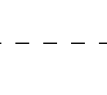 & - & $-\frac{0}{-}-$ & $\frac{1}{1}-$ & $-\frac{1}{1}$ \\
\hline & i̊ำ & $\frac{\text { PR0\% }}{\text { PR5\% }}$ & --1 & --1 & & & & - & - & $-\frac{1}{-}$ \\
\hline
\end{tabular}

\subsubsection{Multiple Stress Creep Recovery (MSCR) Test}

MSCR test was conducted to evaluate the more profound rutting property of CRM binders. MSCR test is the latest enhancement to the Superpave performance graded (PG) asphalt binder specification [18,19]. It is recommended to apply the MSCR test to evaluate the rutting property of PMA binders based on the creep and recovery. The original binder experiences the short-term aging process in the RTFO equipment to perform the test. Then, the same DSR equipment measuring the $\mathrm{G}^{*} / \sin \delta$ is applied to carry out the MSCR test following AASHTO TP 70. The irrevocable creep compliance $\mathrm{J}_{\mathrm{nr}}$ indicates the susceptibility of PMA binders to rutting at high temperatures. The delayed elastic response of the PMA binder can be represented as \% recovery. Thus, high \% recovery implies a considerable elastic component in asphalt binder. Figure 6a shows the change in creep compliance at the $3.2 \mathrm{kPa}$ stress level and the recovery rate of the CRM binder with PR added at $76{ }^{\circ} \mathrm{C}$. The addition of CRM reduced the $\mathrm{J}_{\mathrm{nr}}$ value compared to the base binder without crumb rubber in Figure 6a. In addition, as the rubber content increases, the value decreases, meaning that the addition of rubber is considered to be effective in lowering the nonrecoverable portion of the binder. Not only the CRM but also the PR have the effect of improving plastic deformation properties as showing lower values compared to binders without PR. According to the \%rec results, the higher the rubber content was, the higher the value was. However, unlike the $\mathrm{Jnr}_{\mathrm{nr}}$ results, the percentage of the elastic recovery potion due to the addition of PR was not clear. As some of the results showed relatively large standard deviations, it is considered that there might be an experimental error. Overall, the addition 
of CRM and PR is considered to have a positive effect on plastic deformation resistance based on the elasticity of the binder. In addition, the CRM 10\%, including PE5\% and all CRM $15 \%$, satisfied the maximum $\mathrm{Jnn}_{\mathrm{nr}}$ value to be applied at $76^{\circ} \mathrm{C}$, meaning that other binders failed at this testing temperature considering the elastic property.

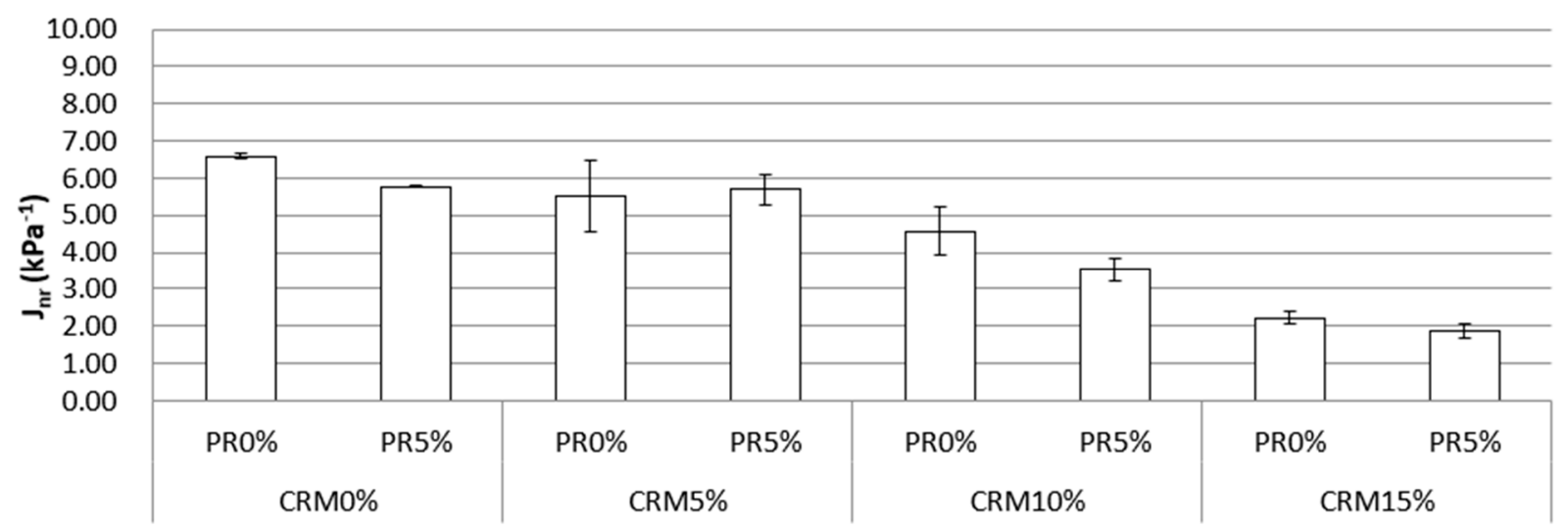

(a)

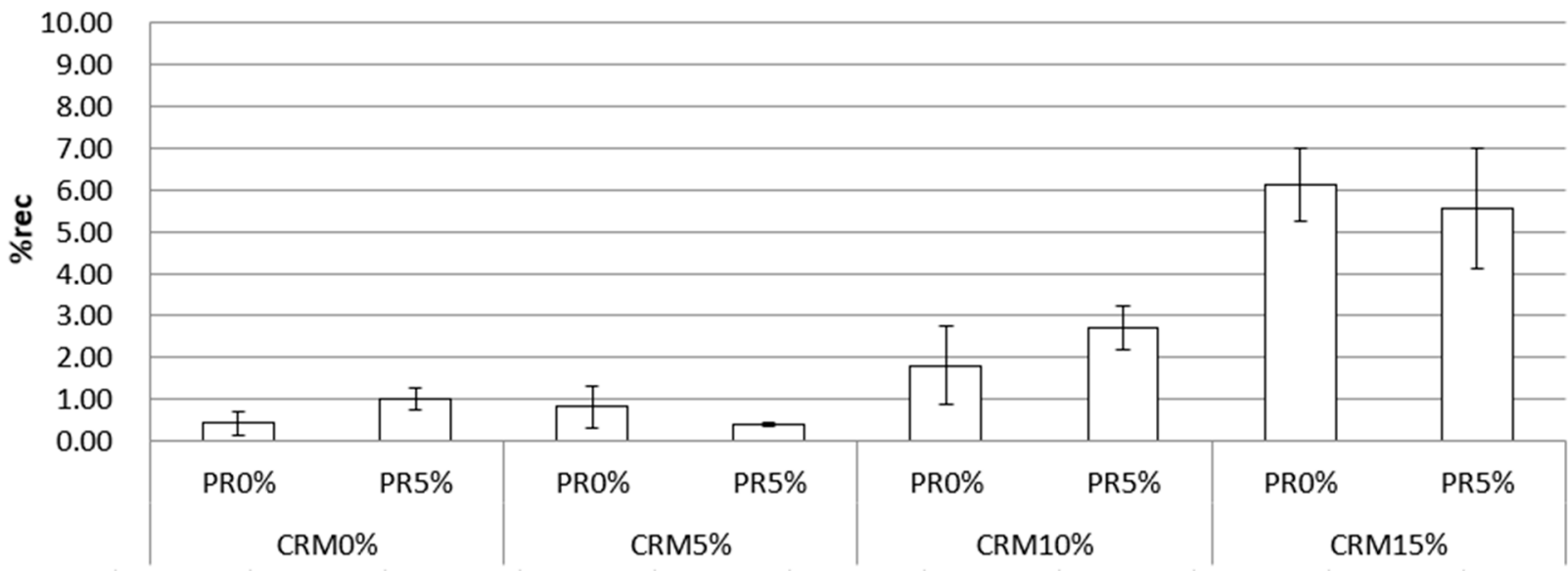

(b)

Figure 6. Variations in creep compliance, percent recovery and percent difference in creep compliance of the CRM binders with $\mathrm{PR}$ at $76{ }^{\circ} \mathrm{C}$; (a) $\mathrm{Jnr}$ and (b) \%rec. Note: The error bar indicates the standard deviation.

Tables 5 and 6 present analyzed statistical significance results of the MSCR as a function of additives content. In statistical analysis of $\mathrm{J}_{\mathrm{nr}}$, it is generally shown that there was significant difference by CRM content when compared with each binder types depending on existence of PR, meaning that the effect of CRM is significant on $\mathrm{J}_{\mathrm{nr}}$ result. However, the results showed that the addition of PR has an insignificant difference in the $\mathrm{Jnn}_{\mathrm{nr}}$ value within each CRM content. According to the results of \%rec, there is a statistically significant difference in general except for the $\mathrm{CRM} \% \%$ binder. In addition, all binders have insignificant difference depending on the addition of PR.

\subsection{Cracking Property}

\subsubsection{Fatigue Cracking at Intermediate Temperature}

In fatigue crack testing with DSR, a lower value is favored as it indicates better cracking resistance. Fatigue crack characteristics are identified based on the $\mathrm{G}^{*} \sin \delta$ value. Figure 7 exhibits measured $\mathrm{G}^{*} \sin \delta$ value of the long-term aged binders. It seems that the higher the CRM content, the lower the $\mathrm{G}^{*} \sin \delta$ of CRM Binder. As the CRM content is increased by $5 \%$, the $\mathrm{G}^{*} \sin \delta$ value is decreased by approximately $10-15 \%$. Regarding the effect of CRM content on $\mathrm{G}^{*} \sin \delta, \mathrm{CRM}$ binders produced at $15 \%$ are deemed to have the highest fatigue cracking resistance. However, the CRM binders modified with PR showed 
less cracking resistance. In each CRM content, the PR-added samples showed an average $80 \%$ increase in $\mathrm{G}^{*} \sin \delta$ value. This indicates that the addition of PR into the CRM binder negatively affects fatigue cracking resistance. Therefore, all CRM binders containing PR showed a bigger $\mathrm{G}^{*} \sin \delta$ value rather than $2000 \mathrm{kPa}$. It means that all binders except for the control CRM binders, including $10 \%$ and $15 \%$, without the PR failed.

Table 5. Statistical analysis results of the $\mathrm{J}_{\mathrm{nr}}$ as a function of CRM content and addition of PR $(\alpha=0.05)$.

\begin{tabular}{|c|c|c|c|c|c|c|c|c|c|c|}
\hline & \multirow{3}{*}{$\mathrm{J}_{\mathrm{nr}}$} & & \multicolumn{8}{|c|}{ CRM Content } \\
\hline & & & \multicolumn{2}{|c|}{$0 \%$} & \multicolumn{2}{|c|}{$5 \%$} & \multicolumn{2}{|c|}{$10 \%$} & \multicolumn{2}{|c|}{$15 \%$} \\
\hline & & & PR0\% & PR5\% & PR0\% & PR5\% & PR0\% & PR5\% & PR0\% & PR5\% \\
\hline \multirow{4}{*}{ 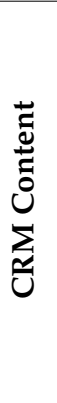 } & $\dot{0}^{\circ}$ & $\begin{array}{l}\text { PR0\% } \\
\text { PR5\% }\end{array}$ & --- & $-\frac{0}{-}-$ & $\begin{array}{c}1 \\
----\end{array}$ & $-\frac{0}{0}-$ & $-\frac{1}{1}-$ & $-\frac{1}{1}-$ & $-\frac{1}{1}--$ & $-\frac{1}{1}-$ \\
\hline & i̊ & $\begin{array}{l}\text { PR0\% } \\
\text { PR5\% }\end{array}$ & -- & & - & $-\frac{0}{-}$ & $\begin{array}{c}0 \\
--- \\
1\end{array}$ & $-\frac{1}{1}-$ & $-\frac{1}{1}$ & $-\frac{1}{1}$ \\
\hline & $\stackrel{8}{0}^{\circ}$ & $\begin{array}{l}\text { PR0\% } \\
\text { PR5\% }\end{array}$ & & & & & - & $\begin{array}{l}0 \\
- \\
-\end{array}$ & $-\frac{1}{1}-$ & $-\frac{1}{1}$ \\
\hline & $\stackrel{\circ}{\stackrel{0}{1}}$ & $\begin{array}{l}\text { PR0\% } \\
\text { PR5\% }\end{array}$ & - & & & & & & - & $-\frac{0}{-}$ \\
\hline
\end{tabular}

0: nonsignificant, 1: significant.

Table 6. Statistical analysis results of the \%rec as a function of CRM content and addition of PR $(\alpha=0.05)$.

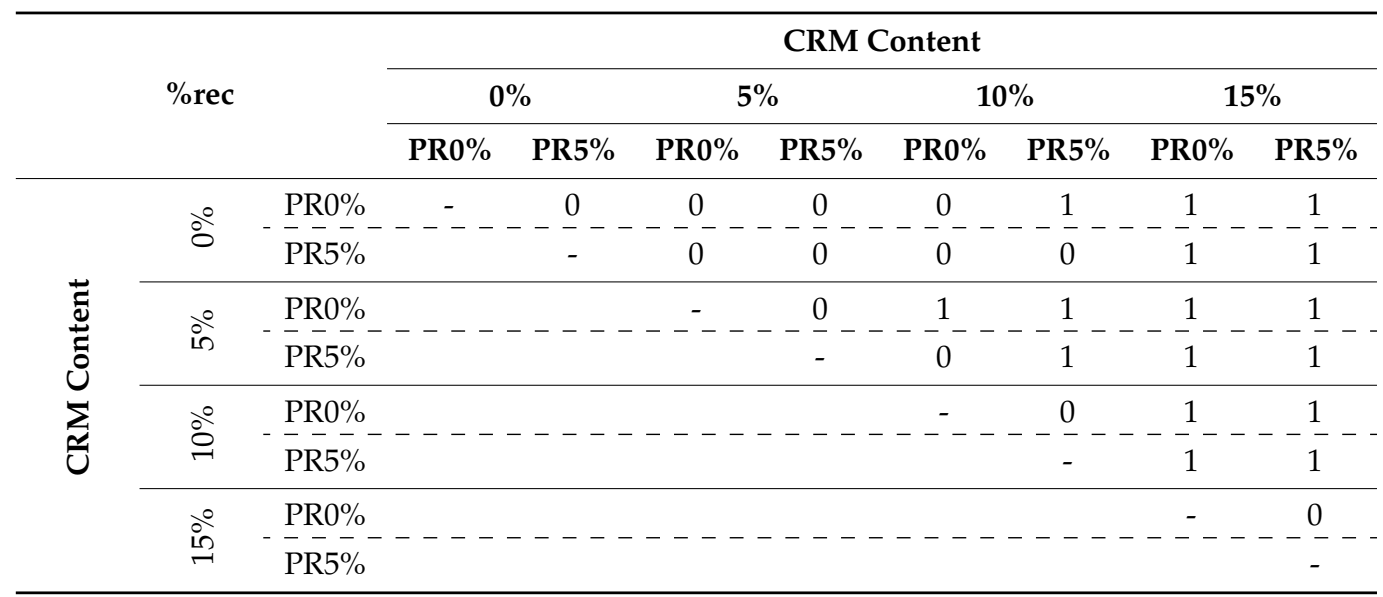

0: nonsignificant, 1: significant.

From ANOVA test results shown in Table 7, the statistical differences of $\mathrm{G}^{*} \sin \delta$ as a function of CRM content is insignificant. Additionally, the difference depending on the PR was found to have a significant effect, at the $5 \%$ level, on $\mathrm{G}^{*} \sin \delta$ of the CRM binders, meaning that the negative effect of PR to increase the $\mathrm{G}^{*} \sin \delta$ values is statistically obvious. 


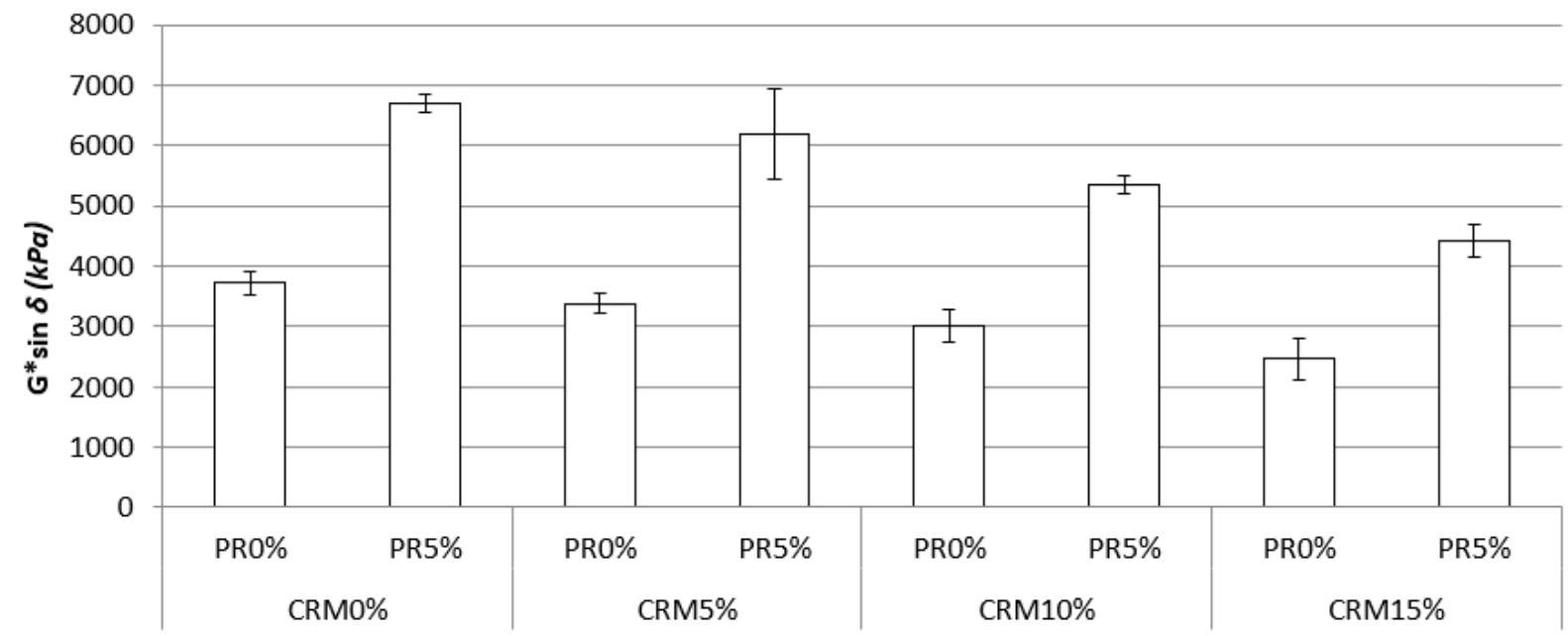

Figure 7. $\mathrm{G}^{*} \sin \delta$ of the CRM binders with PR at $25^{\circ} \mathrm{C}$. Note: The error bar indicates the standard deviation.

Table 7. Statistical analysis results of the $\mathrm{G}^{*} \sin \delta$ as a function of CRM content and addition of PE $(\alpha=0.05)$.

\begin{tabular}{|c|c|c|c|c|c|c|c|c|c|c|}
\hline & \multirow{3}{*}{ PAV } & & \multicolumn{8}{|c|}{ CRM Content } \\
\hline & & & \multicolumn{2}{|c|}{$0 \%$} & \multicolumn{2}{|c|}{$5 \%$} & \multicolumn{2}{|c|}{$10 \%$} & \multicolumn{2}{|c|}{$15 \%$} \\
\hline & & & PR0\% & PR5\% & PR0\% & PR5\% & PR0\% & PR5\% & PR0\% & PR5\% \\
\hline \multirow{5}{*}{ 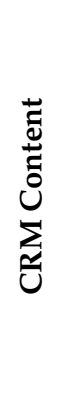 } & $0^{\circ}$ & PR0\% & - & 1 & 0 & 1 & 0 & 1 & 1 & 0 \\
\hline & 0 & PR5\% & & - & 1 & 0 & 1 & 1 & 1 & 1 \\
\hline & i̊ํ & \begin{tabular}{l} 
PR0\% \\
\hdashline-- \\
PR5\%
\end{tabular} & 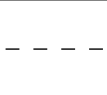 & - & - & $-\frac{1}{-}$ & $\begin{array}{c}0 \\
-1 \\
1\end{array}$ & $-\frac{1}{1}-$ & $\begin{array}{c}0 \\
-1\end{array}$ & $-\frac{1}{1}$ \\
\hline & $\stackrel{\circ}{\circ}$ & $\begin{array}{l}\text { PR0\% } \\
\text { PR5\% }\end{array}$ & --- & --1 & -- & --1 & - & $-\frac{1}{-}-$ & $\frac{0}{1}$ & $--\frac{1}{1}$ \\
\hline & 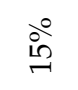 & $\begin{array}{l}\text { PR0\% } \\
-=- \\
\text { PR5\% }\end{array}$ & & & & & & & - & $--\frac{1}{-}$ \\
\hline
\end{tabular}

0: nonsignificant, 1: significant.

\subsubsection{Thermal Cracking Properties at Low Temperature}

The creep stiffness is limited to up to $300 \mathrm{MPa}$ to prevent thermal cracking. In addition, the possibility of low-temperature cracking is reduced when lower stiffness values reduce the tensile stress of the binder. The stiffness and m-value of the CRM binder containing PR were measured at $-12{ }^{\circ} \mathrm{C}$ by the BBR test. Figures 8 and 9 show the creep stiffness and $m$-value results, respectively. The stiffness of the CRM binder tends to decrease as the CRM content increases from $0 \%$ to $15 \%$, which means that as the CRM content increases, the crack resistance of the binder is further improved. Additionally, CRM binders produced with PR generally exhibited higher stiffness than without PR. It is important that the addition of PR is inferior to low temperature cracking, as opposed to its rutting properties at high temperatures. The $m$-value results showed a similar trend. While the $m$-value does not seem to change significantly depending on the CRM content, it is found that all binders containing PR had a lower $m$-value than CRM binders without PR. It is doubtful that the addition of PR increases the brittle part of the asphalt binder. Even though the addition of PR negatively affects thermal cracking property, all binders represented a smaller stiffness value than $300 \mathrm{MPa}$ of maximum value. 


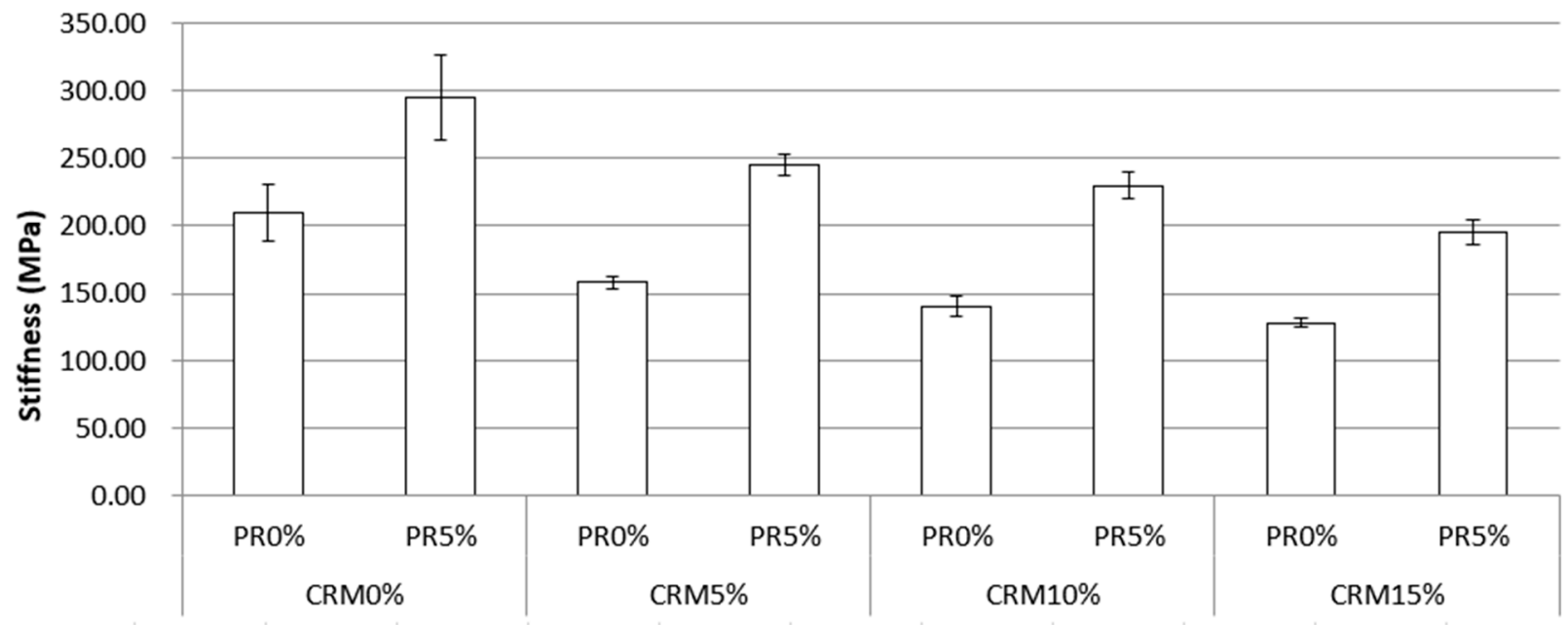

Figure 8. Stiffness at $-12{ }^{\circ} \mathrm{C}$ of the CRM binders with PR. Note: The error bar indicates the standard deviation.

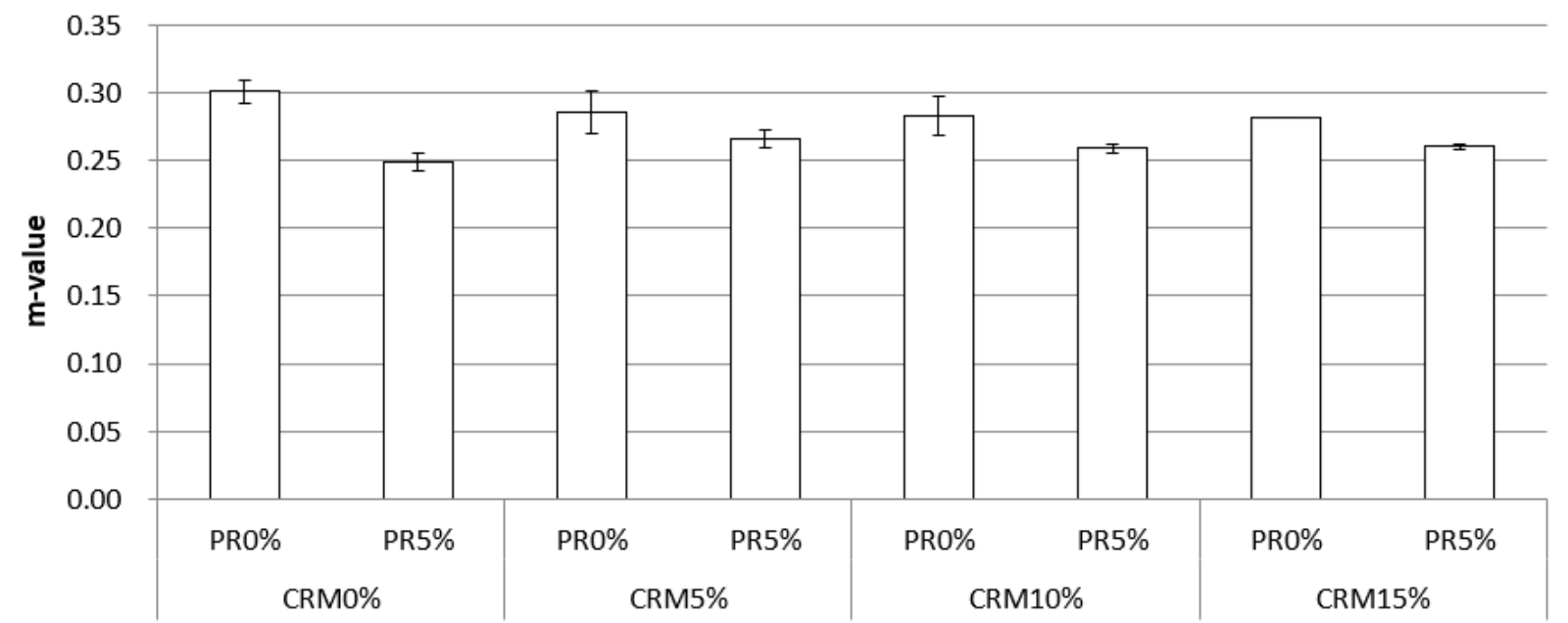

Figure 9. $m$-value at $-12{ }^{\circ} \mathrm{C}$ of the CRM binders with PR. Note: The error bar indicates the standard deviation.

In general, the effect of CRM content on the stiffness value was significant at the 5\% level (Table 8). In addition, the difference by the addition of PR was statistically significant within each CRM content. This result indicates that the double-opposite effect of CRM and PR is evident in impacting the stiffness of asphalt binder. The statistical analysis results of $m$-value are shown in Table 9. The statistical results indicate that there were insignificant differences in m-values of CRM binders as a function of CRM content and PR. 
Table 8. Statistical analysis results of the stiffness as a function of CRM content and addition of PR $(\alpha=0.05)$.

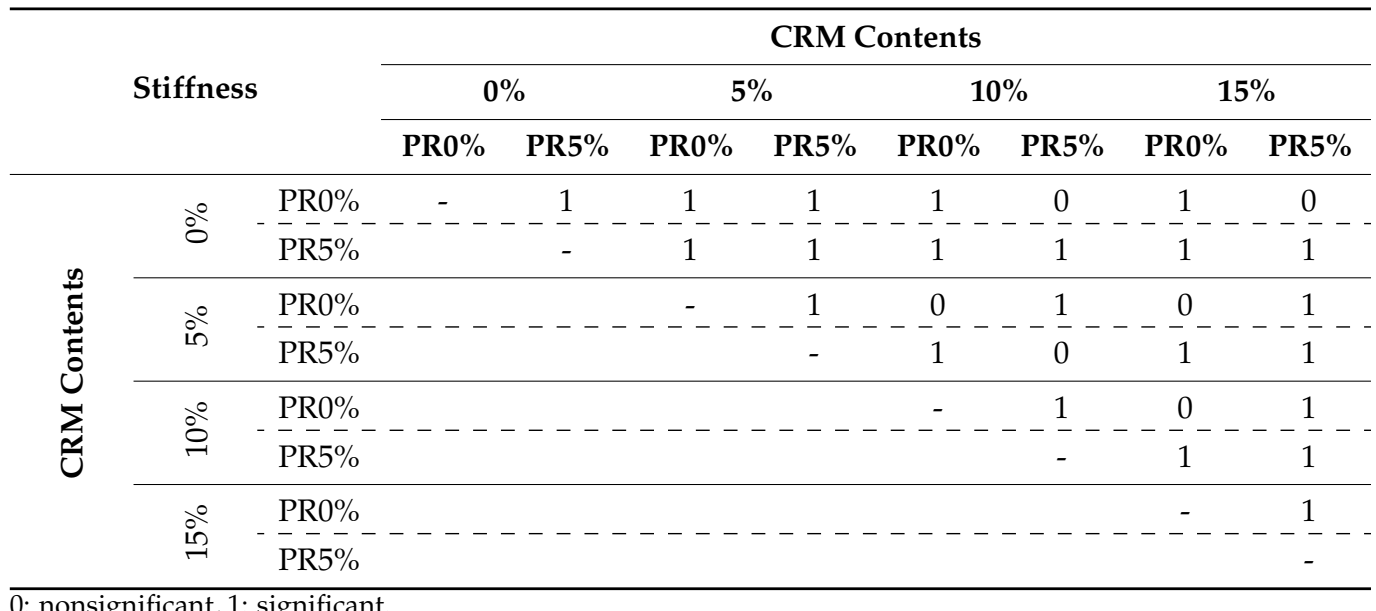

Table 9. Statistical analysis results of the $m$-value as a function of CRM content and addition of PR $(\alpha=0.05)$.

\begin{tabular}{|c|c|c|c|c|c|c|c|c|c|c|}
\hline & \multirow{3}{*}{$m$-Value } & & \multicolumn{8}{|c|}{ CRM Contents } \\
\hline & & & \multicolumn{2}{|c|}{$0 \%$} & \multicolumn{2}{|c|}{$5 \%$} & \multicolumn{2}{|c|}{$10 \%$} & \multicolumn{2}{|c|}{$15 \%$} \\
\hline & & & PR0\% & PR5\% & PR0\% & PR5\% & PR0\% & PR5\% & PR0\% & PR5\% \\
\hline \multirow{5}{*}{ 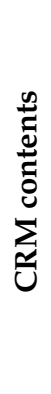 } & $0^{\circ}$ & PR0\% & - & 1 & 0 & 1 & 0 & 1 & 0 & 1 \\
\hline & 8 & PR5\% & & - & 1 & $\overline{0}$ & 1 & 0 & 1 & 0 \\
\hline & î̀ & $\begin{array}{l}\text { PR0\% } \\
\text { PR5\% }\end{array}$ & -- & - & - & $-\frac{0}{-}$ & $\begin{array}{c}0 \\
---- \\
0\end{array}$ & $-\frac{1}{0}$ & $-\frac{0}{0}-$ & $-\frac{1}{0}-$ \\
\hline & $\stackrel{\circ}{\circ}$ & $\begin{array}{l}\text { PR0\% } \\
\text { PR5\% }\end{array}$ & -- & & & & - & $\begin{array}{r}-\frac{1}{-} \\
-\end{array}$ & $-\frac{0}{1}$ & $--\frac{0}{0}$ \\
\hline & $\stackrel{\circ}{i n}$ & $\begin{array}{l}\text { PR0\% } \\
\text { PR5\% }\end{array}$ & & & & & & & - & $-\frac{1}{-}$ \\
\hline
\end{tabular}

0: nonsignificant, 1: significant.

\section{Summary and Conclusions}

Four different CRM contents $(0 \%, 5 \%, 10 \%$, and $15 \%)$ were produced, and $5 \%$ PR is added into each CRM content to examine the effect of PR on CRM binder. An accelerated aging process (RTFO + PAV) was performed to produce artificially aged CRM binders. General performances of CRM binders with PR were evaluated using rotational viscometer, DSR, and BBR targeting viscosity, rutting, and cracking properties. The following conclusions were derived from these test results:

1. The higher CRM content led to an increase in the viscosity at $135{ }^{\circ} \mathrm{C}$. The use of PR also increased binder viscosity. This indicates that it is required to have high production temperature to manufacture the asphalt mixture including CRM and PR.

2. As the CRM percentage increased and PR was added, the rutting characteristics of the CRM binder improved. The application of both additives is more effective in producing a sustainable binder that is less susceptible to rutting at high pavement temperatures.

3. The higher CRM content is considered to have better rutting resistance regarding elastic property according to the MSCR test results. Addition of PR also significantly decreases the $\mathrm{J}_{\mathrm{nr}}$ value. Although it does not clearly have a positive effect on recoverable portion of binder by $\mathrm{PR}$, it is considered that $\mathrm{PR}$ is effective in improving the elastic property considering some potential experimental errors. 
4. From the fatigue cracking test results, it was shown that higher CRM content has better fatigue crack resistance. However, the addition of PR is critical for declining the cracking property.

5. The higher the CRM content, the lower the stiffness; however, the CRM binder including PR had a lower resistance to low-temperature cracking than without PR.

6. It is recommended to conduct a future study to evaluate the effect of PR using different PMA binder or different types of PR which minimize the negative effect of PR on the cracking property. In addition, further study with many other experimental factors, such as different producing methods and testing temperatures, is needed.

Author Contributions: Conceptualization, H.H.K. and M.M.; methodology, H.H.K.; validation, H.H.K., M.M., S.-J.L. and M.-S.L.; formal analysis, H.H.K.; investigation, H.H.K.; resources, M.-S.L.; data curation, H.H.K. and M.M.; writing-original draft preparation, H.H.K.; writing-review and editing, H.H.K., M.M. and S.-J.L.; visualization, H.H.K.; supervision, H.H.K.; project administration, H.H.K.; funding acquisition, S.-J.L. and M.-S.L. All authors have read and agreed to the published version of the manuscript.

Funding: This research was funded by MOLIT and KAIA, project number 21TBIP-C161605-01.

Institutional Review Board Statement: Not applicable.

Informed Consent Statement: Not applicable.

Data Availability Statement: The data used to support the findings of this study are included within the article.

Acknowledgments: This research was supported by the Research Grant from the Korea Agency for Infrastructure Technology Advancement funded by the Ministry of Land, Infrastructure and Transport of the Korean government (Project No: 21TBIP-C161605-01). The authors would like to thank the members of research team, MOLIT and KAIA for their guidance and supports throughout the project.

Conflicts of Interest: There is no conflict of interest regarding the publication of this paper.

\section{References}

1. Bukowski, J.; Youtcheff, J.; Harman, T. The Multiple Stress Creep Recovery (MSCR) Procedure; Office of Pavement Technol: Washington, DC, USA, 2011; pp. 1-9.

2. Chen, T.; Ma, T.; Huang, X.; Guan, Y.; Zhang, Z.; Tang, F. The performance of hot-recycling asphalt binder containing crumb rubber modified asphalt based on physiochemical and rheological measurements. Constr. Build. Mater. 2019, 226, 83-93. [CrossRef]

3. Class, J.B.; Chu, S.G. The viscoelastic properties of rubber-resin blends. I. The effect of resin structure. J. Appl. Polym. Sci. 1985, 30, 805-814. [CrossRef]

4. Hicks, R.G.; Cheng, D.; Duffy, T.; Teesdale, T. Evaluation of rubberized asphalt terminal blends and a preliminary study on warm mix. Report 2010, CP2C-2010-104. Available online: https://journals.sagepub.com/doi/10.3141/2524-01 (accessed on 2 June 2021).

5. Huang, S.C.; Pauli, A.T. Particle size effect of crumb rubber on rheology and morphology of asphalt binders with long-term aging. Road Mater. Pavement Des. 2008, 9, 73-95. [CrossRef]

6. Kim, H.H.; Lee, S.J. Evaluation of rubber influence on cracking resistance of crumb rubber modified binders with wax additives. Can. J. Civ. Eng. 2016, 43, 326-333. [CrossRef]

7. Kim, H. Characterization of Rubberized Binders with Wax Additives; Texas State University: San Marcos, TX, USA, 2016.

8. Kim, H.H.; Mazumder, M.; Lee, M.S.; Lee, S.J. Effect of blending time on viscosity of rubberized binders with wax additives. Int. J. Pavement Res. Technol. 2018, 11, 655-665. [CrossRef]

9. Kim, H.H.; Lee, M.S.; Lee, S.J. Performance evaluation of polymer modified asphalt (PMA) binders containing ground tire rubber (GTR). Int. J. Pavement Res. Technol. 2019, 12, 215-222. [CrossRef]

10. Lee, S.J. Characterization of Recycled Aged CRM Binders. Ph.D. Thesis, Clemson University, Clemson, SC, USA, 2007.

11. Ott, R.L.; Longnecker, M.T. An Introduction to Statistical Methods and Data Analysis; Cengage Learning: Boston, MA, USA, 2008.

12. Tang, J.; Zhu, C.; Zhang, H.; Xu, G.; Xiao, F.; Amirkhanian, S. Effect of liquid ASAs on the rheological properties of crumb rubber modified asphalt. Constr. Build. Mater. 2019, 194, 238-246. [CrossRef]

13. U.S. Tire Manufacturers Association. Scrap Tire Management Summary; U.S. Tire Manufacturers Association: Washington, DC, USA, 2018.

14. Xiao, F.; Zhao, P.W.; Amirkhanian, S.N. Fatigue behavior of rubberized asphalt concrete mixtures containing warm asphalt additives. Constr. Build. Mater. 2009, 23, 3144-3151. [CrossRef] 
15. Xiang, L.; Cheng, J.; Que, G. Microstructure and performance of crumb rubber modified asphalt. Constr. Build. Mater. 2009, 23, 3586-3590. [CrossRef]

16. Yan, K.; Sun, H.; You, L.; Wu, S. Characteristics of waste tire rubber (WTR) and amorphous poly alpha olefin (APAO) compound modified porous asphalt mixtures. Constr. Build. Mater. 2020, 253, 119071. [CrossRef]

17. Zhang, H.; Chen, Z.; Xu, G.; Shi, C. Physical, rheological and chemical characterization of aging behaviors of thermochromic asphalt binder. Fuel 2018, 211, 850-858. [CrossRef]

18. Zhuang, R.H.; Yu, J.Y.; Chang, H.; Zeng, Y.; Lan, X.Y. Effect of warm mix agent on physical and aging properties of crumb rubber modified bitumen. In Materials Science Forum; Trans Tech Publications Ltd.: Bäch, Switzerland, 2019; Volume 944, pp. 1226-1233.

19. Zohuriaan-Mehr, M.J.; Omidian, H. Petroleum resins: An overview. J. Macromol. Sci. Part C Polym. Rev. 2000, 40, 23-49. [CrossRef] 